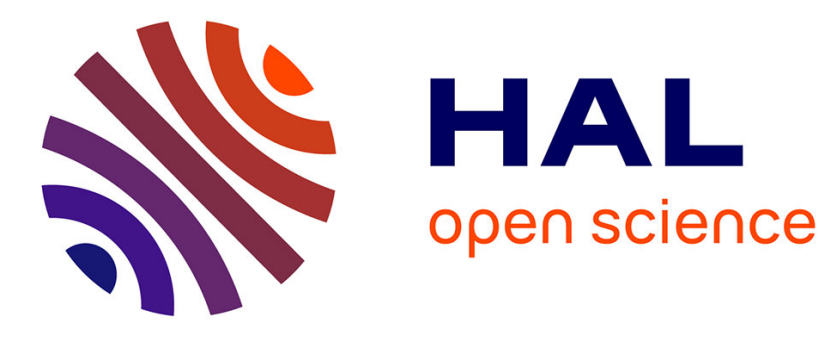

\title{
Cognitive impairment in children with CACNA 1A mutations
}

\author{
Véronique Humbertclaude, Florence Riant, Benjamin Krams, Valérie \\ Zimmermann, Nicolas Nagot, Daniel Annequin, Bernard Echenne, Elisabeth \\ Tournier-Lasserve, Agathe Roubertie, Chrystelle Bonnemains, et al.
}

\section{To cite this version:}

Véronique Humbertclaude, Florence Riant, Benjamin Krams, Valérie Zimmermann, Nicolas Nagot, et al.. Cognitive impairment in children with CACNA 1A mutations. Developmental Medicine and Child Neurology, 2020, 62 (3), pp.330-337. 10.1111/dmcn.14261 . hal-02139175

\section{HAL Id: hal-02139175 \\ https://hal.science/hal-02139175}

Submitted on 2 Jun 2020

HAL is a multi-disciplinary open access archive for the deposit and dissemination of scientific research documents, whether they are published or not. The documents may come from teaching and research institutions in France or abroad, or from public or private research centers.
L'archive ouverte pluridisciplinaire $\mathbf{H A L}$, est destinée au dépôt et à la diffusion de documents scientifiques de niveau recherche, publiés ou non, émanant des établissements d'enseignement et de recherche français ou étrangers, des laboratoires publics ou privés. 


\title{
Cognitive impairment in children with CACNA1A mutations
}

\author{
VERONIQUE HUMBERTCLAUDE ${ }^{1, *}$ | FLORENCE RIANT ${ }^{2,3, *}$ | BENJAMIN KRAMS ${ }^{4}$ VALERIE ZIMMERMANN ${ }^{4}$ | \\ NICOLAS NAGOT ${ }^{5}$ | DANIEL ANNEQUIN ${ }^{6}$ | BERNARD ECHENNE ${ }^{4}$ | ELISABETH TOURNIER-LASSERVE ${ }^{2,3}$ | \\ AGATHE ROUBERTIE 4 \\ EPISODIC SYNDROME CONSORTIUM ${ }^{\dagger}$
}

1 Service de Médecine Psychologique Enfants et Adolescents, CHU Saint Eloi, Montpellier; 2 Laboratoire de Génétique, Groupe hospitalier Lariboisière-Fernand Widal AP-HP, Paris; 3 INSERM UMR-S740, Université Paris 7 Denis Diderot, Paris; 4 Département de Neuropédiatrie, CHU Gui de Chauliac, Montpellier; 5 Centre d'Investigation Clinique, CHU Montpellier, Montpellier; 6 Centre de la Migraine de I'Enfant, Hôpital Trousseau, APHP, Paris; 7 INSERM U 1051, Institut des Neurosciences de Montpellier, Montpellier, France.

Correspondence to Agathe Roubertie, Département de Neuropédiatrie, CHU Gui de Chauliac, 80 Avenue Fliche, 34295 Montpellier, France. E-mail: a-roubertie@chu-montpellier.fr

*These authors contributed equally to the manuscript.

$\uparrow$ Members of the Episodic Syndrome Consortium are listed in Appendix S1 (online supporting information).

\section{ABBREVIATIONS}

Benign paroxysmal torticollis Benign paroxysmal vertigo Benign paroxysmal tonic upgaze

AIM To describe the clinico-radiological phenotype of children with a CACNA1A mutation and to precisely evaluate their learning ability and cognitive status.

METHOD Children between the ages of 3 and 18 years harboring a pathogenic CACNA1A mutation associated with episodic ataxia, hemiplegic migraine, benign paroxysmal torticollis, benign paroxysmal vertigo, or benign paroxysmal tonic upgaze, were enrolled in this crosssectional study. Data concerning psychomotor development, academic performance, educational management, clinical examination at inclusion, and brain imaging were collected. Cognitive assessment was performed using age-standardized scales.

RESULTS Eighteen patients (nine males, nine females; mean age at inclusion: 11y $7 \mathrm{mo}$ [SD $4 \mathrm{y}$ $5 \mathrm{mo}$; range $3 y-17 \mathrm{y} 11 \mathrm{mo}]$ ) from 14 families were enrolled. Eleven patients displayed the coexistence or consecutive occurrence of more than one type of episodic event. Nine patients exhibited abnormal neurological examination at inclusion. Brain magnetic resonance imaging (MRI) showed cerebellar atrophy in five patients. Psychomotor development was delayed in nine patients and academic difficulties were reported by the parents in 15 patients; nine patients were in special education. Impairment of intellectual function was assessed in six of the 12 patients with interpretable Full-scale $I Q$ scores and was more frequent when cerebellar atrophy was present on MRI.

INTERPRETATION Cognitive impairment is commonly associated with CACNA1A mutations. We suggest that CACNA1A-associated phenotype should be considered a neurodevelopmental disorder.

The CACNA1A gene, located on chromosome 19p13, encodes the pore-forming Cav2.1 (alpha 1A) subunit of P/ Q-type $\mathrm{Ca}^{2+}$ channels, which plays a major role in neurotransmitter release throughout the nervous system, especially in the cerebellar Purkinje cells. ${ }^{1}$ Triplet repeat mutations in the CACNA1A gene are associated with a homogeneous phenotype of late onset-spinocerebellar ataxia type 6 (OMIM 183086). ${ }^{2}$ Heterozygous point mutations or deletions of the $C A C N A 1 A$ gene are associated with a heterogeneous spectrum of episodic and/or permanent neurological manifestations. More than 20 years ago, mutations in the CACNA1A gene were identified in patients with hemiplegic migraine (OMIM 141500) and in patients with episodic ataxia type 2 (OMIM 108500). ${ }^{3}$ More recently, single case reports or short case series showed the involvement of $C A C N A 1 A$ mutations in various types of episodic neurological manifestations with or without hemiplegic migraine or episodic ataxia type 2, episodic syndrome that may be associated with migraine (benign paroxysmal torticollis [BPT]), benign paroxysmal vertigo (BPV), benign paroxysmal tonic upgaze (BTU), epileptic seizures, or dyskinesia. ${ }^{4-10}$ Ataxia, with or without cerebellar atrophy, has been reported in adults, and in single case reports of children with $C A C$ $N A 1 A$ mutations. ${ }^{6,11-16}$ Among the chronic neurological manifestations associated with heterozygous CACNA1A mutations, cognitive dysfunction has been suggested in recent years, including developmental delay, learning difficulties, autism, attention-deficit/hyperactivity disorder, intellectual impairment, and epileptic or non-epileptic encephalopathy. ${ }^{6,17-23}$ Until now, the cognitive profile of children with CACNA1A mutations has not been studied systematically in a series of patients.

This study aimed to describe the clinico-radiological phenotype of children with $C A C N A 1 A$ mutations, with 
special focus on psychomotor development and cognitive abilities, and to determine the clinical and genetic factors associated with cognitive dysfunction.

\section{METHOD}

Between July 2011 and February 2016, 18 patients were recruited through the Childhood Episodic Syndromes Study, a large, multicentre, research project on episodic syndromes in children, part of whose results have recently been published. ${ }^{24}$ Patients were included in the study if they were: (1) between 3 and 18 years old; (2) had a pathogenic CACNA1A mutation; and (3) they (or their parents) agreed to undergo clinical and neurocognitive evaluations. Thirteen patients were tested for CACNA1A mutations before the study and were included for clinical evaluation and five had both molecular and clinical evaluation during the multicentre research project (Figure S1, online supporting information). Eleven University Hospitals in France were involved in this cross-sectional study.

The study was carried out in accordance with the Declaration of Helsinki and approved by the Sud-Méditerrannée ethical committee. Written informed consent for clinical data collection and genetic studies was obtained from the patients' legal representative.

\section{Clinical assessment}

The clinical data were collected by seven delegated participating clinicians using a structured questionnaire specifically designed to gather information concerning perinatal events, psychomotor development, familial history, and neurological examination at inclusion. The following data were collected concerning the occurrence of any type of paroxysmal neurological events: type of event (ataxia, BTU, paroxysmal torticollis, vertigo, other forms of movement disorders, hemiplegic or non-hemiplegic migraine, epileptic seizures), age at onset, duration of the episodes, treatments, and outcome at inclusion. Episodic events were diagnosed according to International Headache Society criteria $^{25-27}$ or diagnosis criteria accepted in the literature, this is summarized in Table SI (online supporting information). Magnetic resonance imaging (MRI) data were reviewed by an experienced neuroradiologist (NL, see Appendix S1) and a paediatric neurologist (AR).

Information concerning rehabilitation (speech, occupational, or psychomotor therapy) for difficulties in academic performance, specific assistance in regular school (services provided by the Ministry of Education in France such as computer use or human assistance), and education in special schools were collected from the medical files and during familial interview at inclusion.

Standardized cognitive scales were administered according to the child's age: the Wechsler Preschool and Primary Scale of Intelligence, Third Edition for children under 7 years, the Wechsler Intelligence Scale for Children, Fourth Edition for children between the ages of 5 and 16 years 11 months, or the Wechsler Adult Intelligence Scale, Third Edition for children older than 16 years.
- Cognitive disabilities and academic difficulties are common in children with CACNATA mutations associated with episodic syndromes.

- Cognitive function ranges from normal to moderate intellectual disorder in wheelchair-dependent children.

- Patients with vermian atrophy are at a higher risk of cognitive impairment.

\section{Genetic assessment}

Screening of the CACNA1A gene was performed by sequencing and quantitative multiplex polymerase chain reaction of short fluorescent fragments analysis. The mutations present in the patients were considered as deleterious according to the following criteria: they were mutations leading to a stop codon or they had already been reported in families experiencing hemiplegic migraine or episodic ataxia (p.T666M, p.G677R, p.R1352Q); they appeared de novo (p.Y1706_I1709del) or were: (1) absent in data bases; (2) prediction tools (polyphen 2, Scale-Invariant Feature Transform, Align Grantham Variation and Grantham Deviation, and mutation taster) gave results in favor of a deleterious effect on the gene; (3) they were localized in a P-loop domain critically implicated in channel function; (4) the patient's phenotype was typical of a CACNA1A linked disease; and (5) they cosegregated with the disease in the tested family members (p.C1417W, p.T1458M).

\section{Statistical analysis}

Patients' characteristics were presented using median and interquartile range (IQR), mean and standard deviation (SD), or range for continuous variables, frequencies, and proportions for categorical variables.

Groups of patients (defined by deficit in intellectual function and cerebellar atrophy) were compared using Student's $t$ or Wilcoxon-Mann-Whitney $U$ tests, depending on the normality of the distributions tested with ShapiroWilk test, for continuous variables and Fisher's exact test for categorical ones.

Statistical bilateral significance threshold was set at $5 \%$. Statistical analyses were performed using SAS, version 9.1 (SAS Institute, Cary, NC, USA).

\section{RESULTS}

Results are reported in Table SII (online supporting information).

\section{Population}

Eighteen patients (nine males, nine females) from 14 families were enrolled, including three sib-pairs (patients 4 and 5,7 and 8, 12 and 13) and one pair of first cousins (patients 15 and 16). The past medical history of the patients was unremarkable. The mean age at inclusion was 11 years 7 months (SD 4y $5 \mathrm{mo}$; range $3 \mathrm{y}-17 \mathrm{y} 11 \mathrm{mo}$ ). Patients 7 , 8, 12 , and 18 have been reported elsewhere. ${ }^{4,12,28}$

Fourteen different mutations were identified: eight mutations leading to a stop codon, one splice site mutation, and five missense mutations (three had already been reported and two were novel). 


\section{Episodic events}

The episodic events considered in the patients were episodic ataxia, hemiplegic migraine, BTU, BPT, and BPV. Details are shown in Table SIII (online supporting information). Seven patients exhibited only one type of episodic event at last follow-up: episodic ataxia occurred in three patients, hemiplegic migraine in two patients, and BTU and BPT in one patient each. Eleven patients presented a combination of various episodic events. Episodic ataxia or hemiplegic migraine occurred in 15 of 18 patients and were preceded by infantile episodic events (BTU, BPT, or $\mathrm{BPV}$ ) in five out of 15 patients. Altogether, episodic ataxia occurred in 11 patients, hemiplegic migraine in five patients, BTU in four patients, BPT in three patients, and BVP in one patient. Two patients presented with seizures and myoclonus was reported in one patient.

The first episodic manifestation occurred at a median age of 24 months (IQR $8 \mathrm{mo}-5 \mathrm{y} 7 \mathrm{mo}$; range $2 \mathrm{mo}-14 \mathrm{y}$ ). BTU, BPT, and BPV were the earliest manifestations in eight patients, with an onset before 4 years of age in all patients, and in the first year of life in six out of eight patients. The number of episodes varied widely. In the eight patients with BTU, BPT, or BPV, the episodic manifestations were considered cured at the time of inclusion, with a median duration of disease of 16 months (IQR 14$23 \mathrm{mo}$; range $13 \mathrm{mo}-6 \mathrm{y} 3 \mathrm{mo}$ ).

Episodic ataxia was the first manifestation in six patients and followed another type of episodic event in five patients. The median age at onset was 36 months (IQR $18 \mathrm{mo}-9 \mathrm{y} 6 \mathrm{mo}$; range $1 \mathrm{mo}-13 \mathrm{y})$. The frequency of episodes varied widely among the patients, ranging from some per year up to almost daily episodes (600 per year in one patient). Hemiplegic migraine occurred as a first phenotype in four patients (patients 15-18), and followed another phenotype in one patient (patient 9). The median age of the start of hemiplegic migraine was 9 years (IQR 7-10y; range $4-14 y$ ). The number of episodes during the first year was less or equal to 12 per year in four out of five patients with hemiplegic migraine and varied widely at follow-up. Episodic ataxia and hemiplegic migraine were considered ongoing manifestations at the time of enrollment in all the patients.

Information concerning treatment of the episodic events was collected in 10 patients with various phenotypes: episodic ataxia (six patients), hemiplegic migraine (three patients), migraine (three patients) (Table SIV, online supporting information). Acetazolamide was effective in one of five patients with episodic ataxia and in the two patients with hemiplegic migraine. Lamotrigine resulted in no effect (one of three patients) or aggravation (two of three patients) with episodic ataxia.

\section{Neuropsychological assessment}

Data concerning psychomotor development, neurological examination, academic performance, and cognitive assessment are detailed in Table SII and summarized in Table I.

\section{Development and neurological examination at enrollment}

Nine patients presented with motor and/or language developmental delay. At the time of enrollment, neurological examination was abnormal in nine patients. Nystagmus was observed in seven patients, associated with cerebellar signs or unsteadiness in three patients, including one severely affected patient with intellectual disability, dyskinesia, and inability to walk alone (patient 17). Cerebellar signs with hypotonia or isolated hypotonia were disclosed in two other patients. Three patients exhibited early-onset nonprogressive cerebellar signs, mimicking congenital ataxia (patients 4, 14, and 17). No other neurological symptoms were recorded (including autistic features).

\section{Academic performance and rehabilitation therapy}

Significant difficulties in academic performance were reported in 15 patients. Nine patients attended special schools; among the nine patients who were in a regular school, four benefited from specific learning assistance. Thirteen among the 18 patients benefited from rehabilitation (speech and/or occupational, and/or fine motor rehabilitation) therapy.

\section{Cognitive assessment}

IQ was evaluated in 16 patients: two with the Wechsler Preschool and Primary Scale of Intelligence, Third Edition, 13

Table I: Psychomotor development, neurological examination, learning disabilities, educational management, and cognitive assessment of the patients

Number of affected patients/number of

Neuropsychological assessment patients with known data

Neurological examination at inclusion

Abnormal

$9 / 18$

Nystagmus

Nystagmus+cerebellar

$4 / 18$

signs or unsteadiness

Cerebellar signs

Hypotonia

Psychomotor

Motor delay

delay

Language delay

Schooling

Difficulties in

academic

performance

according to families

Special education

school

Regular school with

specific learning

assistance

Regular school

without specific

learning assistance

Rehabilitation

Total

Speech therapy

Occupational therapy

Psychomotricity

Full-scale IQ

$<70$

$70-79$

$80-119$

$3 / 18$

$1 / 18$

$1 / 18$

$6 / 18$

$6 / 16$

$15 / 18$

$\geq 120$
$9 / 18$

$5 / 18$

$4 / 18$

$13 / 18$

$13 / 18$

$3 / 18$

$5 / 18$

$6 / 12$

$4 / 12$

2/12

$0 / 12$ 
with the Wechsler Intelligence Scale for Children, Fourth Edition, and one patient with the Wechsler Adult Intelligence Scale, Third Edition (Table SII). Two families completed the study but refused cognitive evaluation. Full-scale IQ was not interpretable in four patients because of excessive discrepancy among the subscales; therefore, Full-scale IQ scores were available in 12 patients. Moderate intellectual disability (Full-scale IQ<50) was present in four out of 12 patients, mild intellectual disability (50-69) in two out of 12 patients; four out of 12 patients had borderline intellectual disability (70-79). Full-scale IQ was in the average range (80-119) in two out of 12 patients, and no patient had an IQ in the superior range $(\geq 120$; Fig. 1). Detailed analysis of IQ scores in the whole group of patients did not reveal a specific pattern of cognitive impairment.

\section{Brain imaging}

Twenty-eight MRI scans were available for the 18 patients. Atrophy of the superior part of the cerebellar vermis was detected in five patients (Fig. 2). The atrophy was present at 4 years and 1 month (patient 14), 11 years and 9 months (patient 9, for whom it was absent at 4y $11 \mathrm{mo}$ ), 12 years and 9 months (patient 10), 15 years 5 months (patient 5), and 15 years 9 months (patient 17). Three patients exhibited episodic ataxia and two had hemiplegic migraine, preceded by BPV in one patient. Of the five patients, four had an abnormal neurological examination: one had isolated hypotonia and three had a nystagmus, associated with cerebellar signs for two of them. Four of the five patients exhibited a deficit in intellectual function, and patient 9 did not undergo IQ assessment.

\section{Family history}

The occurrence of episodic manifestation appeared to be sporadic in six patients. The parents of patient 1 and mother of patient 10 did not have the mutation that was found in their child. The father of patient 9 was an asymptomatic carrier. The other parents were not available for testing.

The eight other patients were familial forms. The mutation was present in a total of 20 additional relatives (Fig. 3). Symptomatic family members of patients 15 and 16 with mutations exhibited the same phenotype (severe attacks of hemiplegic migraine without cognitive dysfunction). In the other seven families, intrafamilial phenotype variability was observed (Table SII). In particular, various associations of BTU, BPT, episodic ataxia, migraine, and cognitive dysfunction were observed in six members of the family affected by the stop mutation c. $2206 \mathrm{C}>\mathrm{T}$ (two sisters, [patients 7 and 8], their mother, a cousin, and a maternal uncle). ${ }^{4}$ BTU and episodic ataxia were associated in five of the 18 families, successively in the same patient (patients 1,2,3, and the cousin of patients 7 and 8 ) or in the same family (two sisters, patients 4 and 5).

\section{Correlations}

Deficit in intellectual function (Full-scale IQ $<70$ in six of 12 patients) tended to be correlated with cerebellar atrophy on brain MRI (four of six patients with Full-scale IQ $<70$ vs zero of six patients with Full-scale IQ $\geq 70, p=0.06$ ). No significant relation could be established between a deficit in intellectual function and sex, young age at onset of the first episodic event, type of episodic event, and occurrence

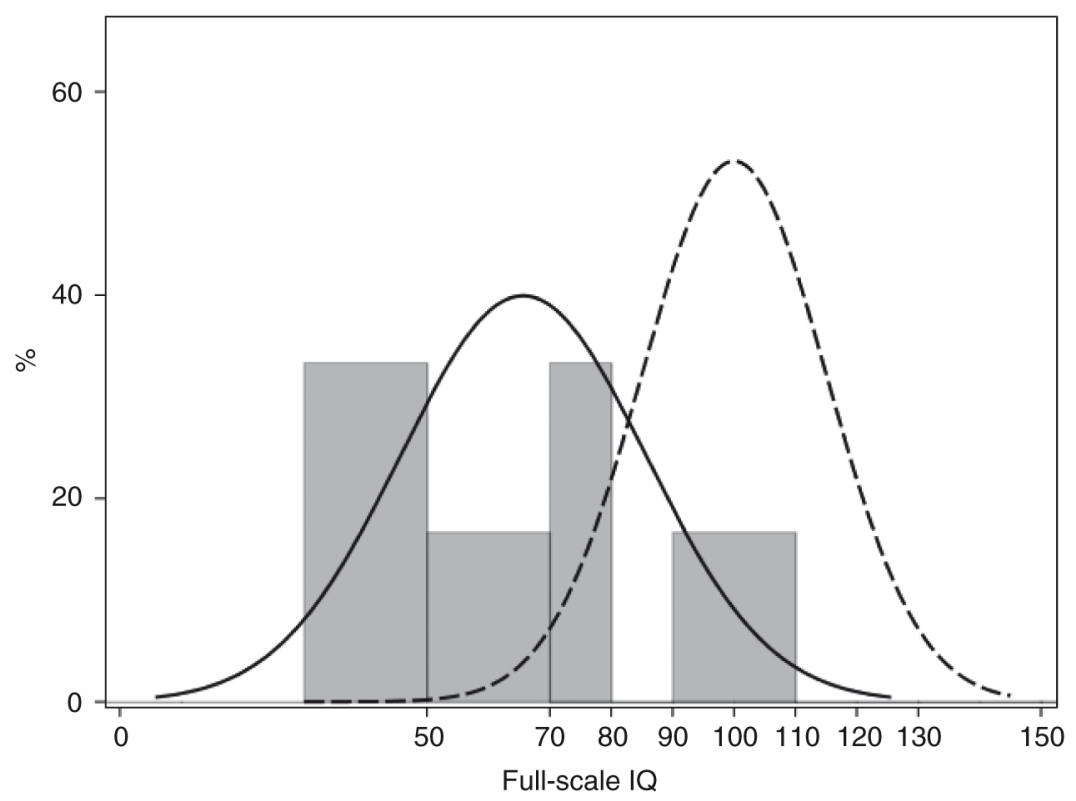

Figure 1: Distribution of the Full-scale IQ score (16 patients). This figure demonstrates the increased incidence of patients with low (<70) or border line $(<80)$ I0 among patients with a CACNA1A mutation. Solid line, general population; dotted line, patients with a CACNA1A mutation; grey bars, number of patients. 


\section{(a)}

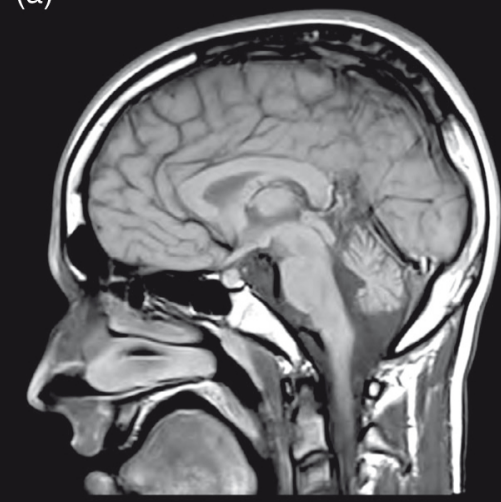

(c) (b)

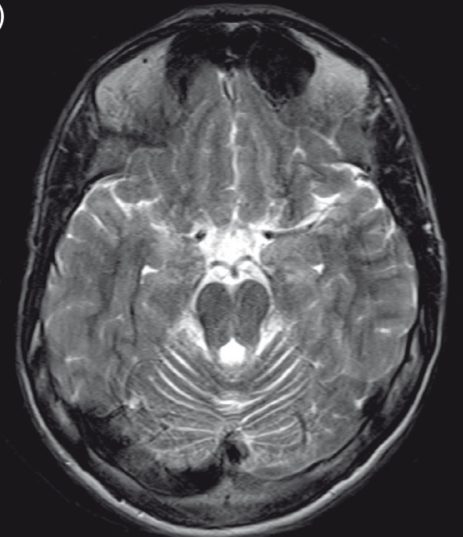

(d)

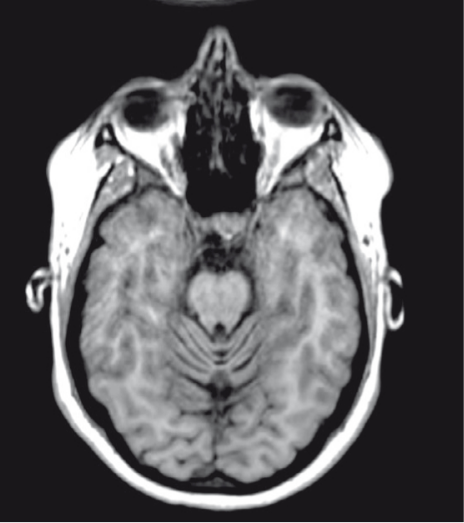

Figure 2: Brain imaging illustrating the vermian atrophy in (a,b) patient 17 and (c,d) patient 9. (a) Sagittal T1 (b) and axial T2 images, cerebellar atrophy mainly involving the superior vermis; (c) sagittal (d) and axial T1 images, cerebellar atrophy involving the superior and posterior vermis with enlarged primary fissure.

of various types of episodic events, abnormal neurological examination, or type of mutation.

The five patients with cerebellar atrophy exhibited motor delay more frequently than patients with normal brain MRI (four of five patients vs two of 13 patients, $p=0.021)$. The proportion of stop mutations was lower in patients with cerebellar atrophy (one of five patients vs 10 of 13 patients, $p=0.047)$. Patients with abnormal MRI tended to be older (mean age [SD] 14y [2y $11 \mathrm{mo}$ ] vs $10 \mathrm{y}$ $8 \mathrm{mo}$ [ $4 \mathrm{y} 7 \mathrm{mo}$ ], $p=0.15$ ). No significant association could be established between cerebellar atrophy and sex, young age at onset of the first episodic event, abnormal neurological examination, and type of episodic events or occurrence of various types of episodic events.

\section{DISCUSSION}

This study describes the clinical and radiological phenotype of 18 children from 14 families with CACNA1A mutations. The patients had a detailed clinical description and benefited from a standardized neurological examination and evaluation of psychomotor development and academic performance, and a cognitive assessment. They also underwent neuroimaging. Our results confirm a diversity of episodic attacks in the patients and a frequent association of neurological abnormalities, in particular, an abnormal cognitive profile.

Precise cognitive evaluations are the main contribution of our study. Recently, Indelicato et al. ${ }^{23}$ reported cognitive and behavioral features in a series of patients with CACNA1A mutations. However, the authors performed a retrospective analysis of data extracted from a database initially developed for another objective, therefore the protocol assessment of cognitive function was not uniform. Our study reports the first series performed with prospective and standardized neuropsychological assessment. It shows that cognitive disabilities are associated with CACNA1A mutations in half of the children with available data, and that cognitive dysfunction is heterogeneous, ranging from a moderate disorder of intellectual development in wheelchair dependent patients to mild difficulties at school. The analysis of the different subtests of the Full-scale IQ testing did not disclose a specific cognitive profile; several domains of cognitive function were impaired in our patients (data not shown). Autistic symptoms that have been previously reported in two families with episodic ataxia type 2 were not detected in our patients. ${ }^{21}$ Vermian atrophy was linked to a higher risk of cognitive dysfunction. 


\section{Familial cases}
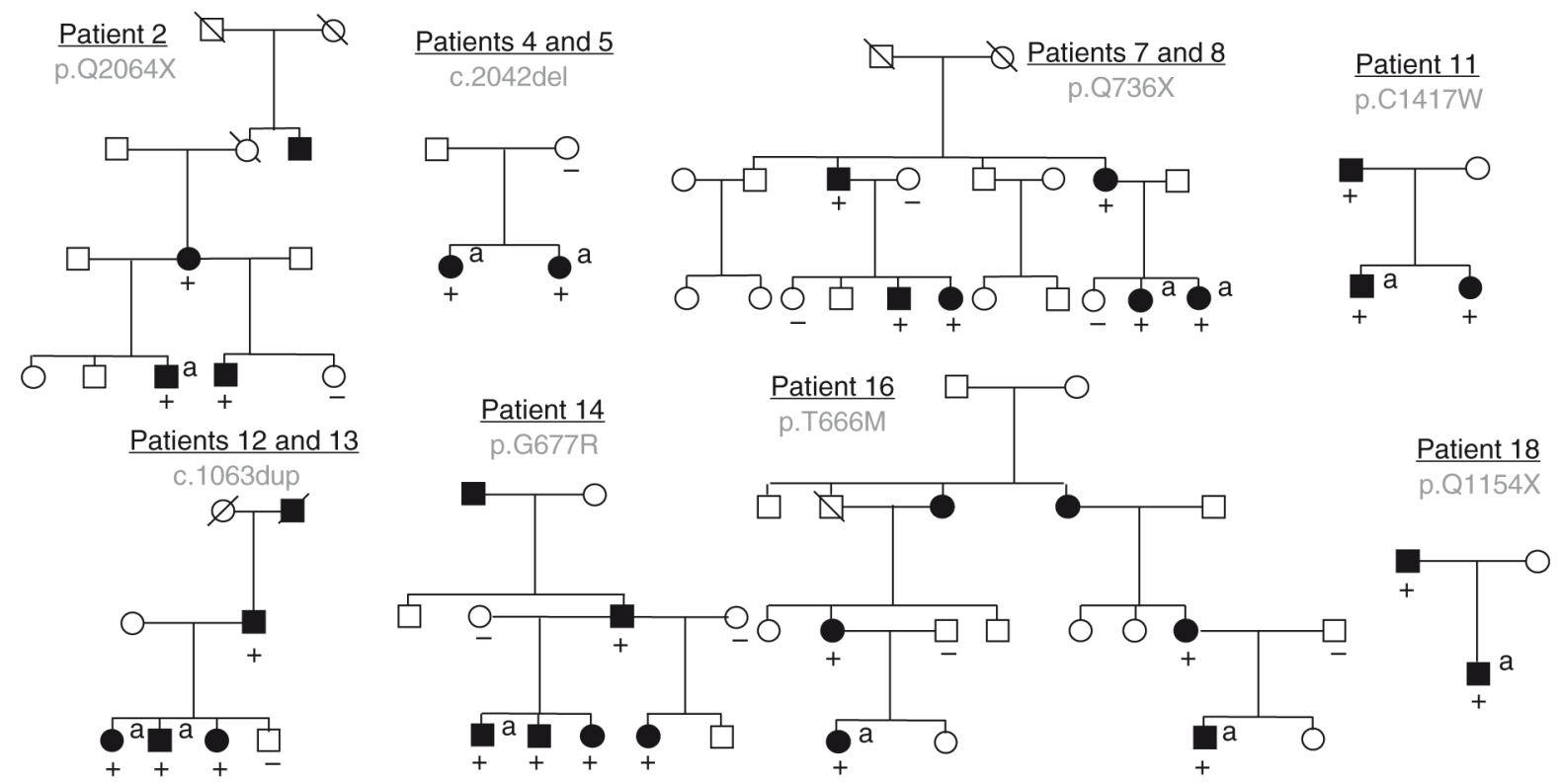

Sporadic cases
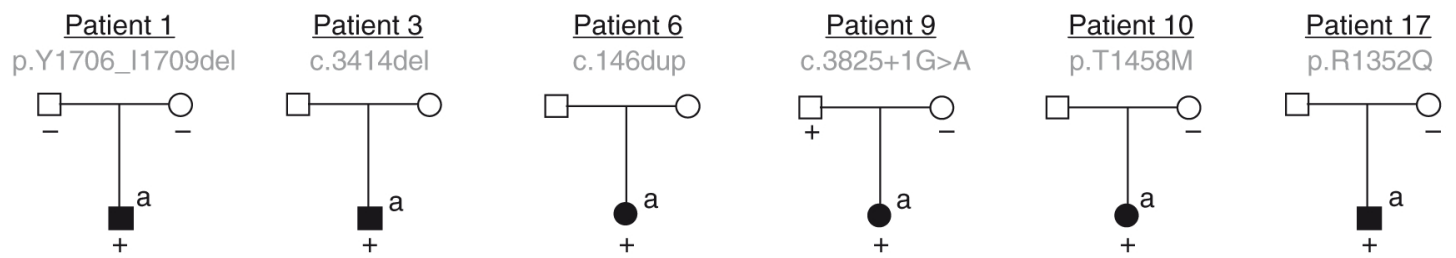

Figure 3: Pedigrees of the patients. Squares represent males and circles represent females. Black symbols represent individuals with episodic symptoms (hemiplegic migraine, episodic ataxia, tonic upgaze, or paroxystic vertigo). White symbols indicate unaffected individuals, and symbols with a diag-

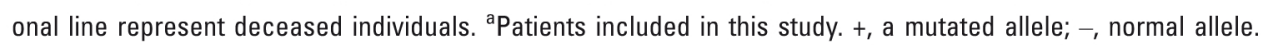

The small size of our patient sample represents a clear limitation if this work, especially regarding establishing a correlation without considering the possible within-family correlations. Given the young age of some patients at inclusion, the results concerning academic difficulties and rehabilitation might underestimate these difficulties and the need for rehabilitation in patients with CACNA1A mutations. Recently, pharmaco-sensitive, but also devastating drug resistant epilepsy has been reported in patients with a $C A C N A 1 A$ mutation; ${ }^{19,29}$ however, the prevalence of epilepsy in patients with a $C A C N A 1 A$ mutation is still unknown. Given that our patients were recruited from the Childhood Episodic Syndromes Study and the database from Lariboisiere laboratory, which researches migraine and syndromes associated with migraine, patients with epilepsy and a $C A C N A 1 A$ mutation might be under represented in our series. In fact, only two patients from our series exhibited epilepsy (absence epilepsy/myoclonus), therefore, our study cannot provide further clues to the issue of the role of epilepsy in cognitive impairment in patients with CACNA1A mutations.
Our study shows that the phenotype of the patients with CACNA1A mutations is highly variable in terms of diversity of clinical manifestations, but also in terms of an association of several types of symptoms, as summarized in Figure S2 (online supporting information). Symptoms include non-epileptic manifestations (ataxia, torticollis, vertigo, tonic upward gaze, migraine), and epileptic events (absence seizures, myoclonus). A combination of several types of episodic syndromes was present in two out of three of our patients, either concomitant or evolving from one type to another. Permanent neurological abnormalities were also present in half of the patients at inclusion, consisting of variable degrees of cerebellar dysfunction (nystagmus, ataxia, hypotonia), with or without vermian atrophy. Our study confirms that infantile-onset episodic syndromes, such as BTU or BPT, may be precursor of CACNA1A-related episodic ataxia or hemiplegic migraine ${ }^{8-10}$ since in one-third of the patients, occurrence of episodic ataxia or hemiplegic migraine was preceded by BTU, BPT, or BPV.

Our study clearly highlights the wide phenotypic spectrum associated with $C A C N A 1 A$ mutations, regarding age 
at onset of the symptoms, cognitive profile (ranging from typical to moderate disability), episodic syndromes (diversity of the syndromes), and neurological examination (from unremarkable to variable degrees of cerebellar signs). Three patients presented an early-onset ataxia mimicking congenital ataxia with episodic syndromes. Early-onset non-progressive ataxia/hypotonia that might be isolated or might overwhelm episodic neurological manifestations represents a recently recognized mode of presentation of CACNA1A mutations, ${ }^{6,12,14,16,20}$ which has probably been underdiagnosed until recently.

Finally, our study also shows a large intrafamilial clinical heterogeneity with a classic presentation of well-known diseases related to CACNA1A (episodic ataxia type 2 and hemiplegic migraine) and a less typical presentation for which the diagnosis is often more difficult to make. Interviewing patients about their relatives can help establish the correct diagnosis and lead to appropriate care.

In conclusion, our results confirm that $C A C N A 1 A$ mutations are associated with a wide phenotypic spectrum including various forms of infantile or childhood onset episodic neurological events, neurological and cognitive abnormalities, and familial heterogeneity. The phenotypic spectrum associated with pathogenic mutations of $C A C$ NA1A includes non-epileptic paroxysmal events, paroxysmal epileptic manifestations, permanent neurological symptoms, and cognitive disabilities. Identification of $C A C$ NA1A mutations must lead to close follow-up of psychomotor development and academic performance, so early management and care can be proposed. Patients with vermian atrophy are at a higher risk of cognitive dysfunction. We propose that a $C A C N A 1 A$-associated phenotype may present as a neurodevelopmental disorder.

\section{ACKNOWLEDGEMENTS}

We acknowledge the patients and their families for participating in the study. We thank Dr Lagavulin for his helpful discussions. This study was supported by the Clinical Research Hospital Program from the French Ministry of Health 2010 (Project number 14-12). The authors have stated that they had no interests which might be perceived as posing a conflict or bias.

\section{REFERENCES}

1. Mori Y, Friedrich T, Kim MS, et al. Primary structure and functional expression from complementary DNA of a brain calcium channel. Nature 1991; 350: 398-402.

2. Zhuchenko O, Bailey J, Bonnen P, et al. Autosomal dominant cerebellar ataxia (SCA6) associated with small polyglutamine expansions in the alpha 1A-voltage-dependent calcium channel. Nat Genet 1997; 15: 62-9.

3. Ophoff RA, Terwindt GM, Vergouwe MN, et al. Familial hemiplegic migraine and episodic ataxia type-2 are caused by mutations in the $\mathrm{Ca}^{2+}$ channel gene CACNL1A4. Cell 1996; 87: 543-52.

4. Roubertie A, Echenne B, Leydet J, et al. Benign paroxysmal tonic upgaze, benign paroxysmal torticollis, episodic ataxia and CACNA1A mutation in a family. 7 Neurol 2008; 255: 1600-2

5. Cuenca-León E, Corominas R, Fernàndez-Castillo N et al. Genetic analysis of 27 Spanish patients with hemiplegic migraine, basilar-type migraine and childhood periodic syndromes. Cephalalgia 2008; 28: 1039 47.

6. Blumkin L, Michelson M, Leshinsky-Silver E, Kivity S, Lev D, Lerman-Sagie T. Congenital ataxia, mental retardation, and dyskinesia associated with a novel CACNA1A mutation. 7 Child Neurol 2010; 25: 892-7.

7. Blumkin L, Leshinsky-Silver E, Michelson M, et al. Paroxysmal tonic upward gaze as a presentation of denovo mutations in CACNA1A. Eur 7 of Paediatr Neurol 2015; 19: 292-7.

8. Vila-Pueyo M, Gené GG, Flotats-Bastardes $M$, et al. A loss-of-function CACNA1A mutation causing benign paroxysmal torticollis of infancy. Eur 7 Paediatr Neurol 2014; 18: 430-3.

9. Shin M, Douglass LM, Milunsky JM, Rosman NP. The genetics of benign paroxysmal torticollis of infancy. 7 Cbild Neurol 2016; 31: 1057-61.

10. Tantsis EM, Gill D, Griffiths L, et al. Eye movement disorders are an early manifestation of CACNA1A mutations in children. Dev Med Child Neurol 2016; 58: 639-44.

11. Guerin AA, Feigenbaum A, Donner EJ, Yoon G. Stepwise developmental regression associated with novel CACNA1A mutation. Pediatr Neurol 2008; 39: 363-4.

12. Bertholon $\mathrm{P}$, Chabrier S, Riant F, Tournier-Lasserve E, Peyron R. Episodic ataxia type 2: unusual aspects in clinical and genetic presentation. Special emphasis in childhood. 7 Neurol Neurosurg Psychiatr 2009; 80: 1289 92.

13. Nachbauer W, Nocker M, Karner E, et al. Episodic ataxia type 2: phenotype characteristics of a novel CACNA1A mutation and review of the literature. 7 Neurol 2014; 261: 983-91.

14. Travaglini L, Nardella M, Bellacchio E, et al. Missense mutations of CACNA1A are a frequent cause of autosomal dominant nonprogressive congenital ataxia. Eur 7 Paediatr Neurol 2017; 21: 450-6.

15. Riant F, Lescoat C, Vahedi K, et al. Identification of CACNA1A large deletions in four patients with episodic ataxia. Neurogenetics 2009; 11: 101-6.

16. Luo X, Rosenfeld JA, Yamamoto S, et al. Clinically severe CACNA1A alleles affect synaptic function and neurodegeneration differentially. PLoS Genet 2017; 13: e1006905.

17. Vahedi K, Denier C, Ducros A, et al. CACNA1A gene de novo mutation causing hemiplegic migraine, coma, and cerebellar atrophy. Neurology 2000; 55: 1040-2.

18. Freilinger $\mathrm{T}$, Bohe $M$, Wegener B, Müller-Myhsok B, Dichgans M, Knoblauch H. Expansion of the phenotypic spectrum of the CACNA1A gene T666M mutation: a family with familial hemiplegic migraine type 1 , cerebellar atrophy and mental retardation. Cephalalgia 2008; 28: 403-7.

19. Epi4K Consortium. De novo mutations in SLC1A2 and CACNA1A are important causes of epileptic encephalopathies. Am 7 Hum Genet 2016; 99: 287-98.

20. Weyhrauch DL, Ye D, Boczek NJ, et al. Whole exome sequencing and heterologous cellular electrophysiology studies elucidate a novel loss-of-function mutation in the CACNA1A-encoded neuronal P/Qtype calcium channel in a child with congenital hypotonia and developmental delay. Pediatr Neurol 2015; 55: $46-51$

21. Damaj L, Lupien-Meilleur A, Lortie A, et al. CACNA1A haploinsufficiency causes cognitive impairment, autism and epileptic encephalopathy with mild cerebellar symptoms. Eur 7 Hum Genet 2015; 23: 1505-12.

22. Camia F, Pisciotta L, Morana G, et al. Combined early treatment in hemiplegic attacks related to CACNA1A encephalopathy with brain oedema: Blocking the cascade? Cepbalalgia 2017; 37: 1202-6. 
23. Indelicato $E$, Nachbauer $W$, Karner $E$, et al. The neuropsychiatric phenotype in CACNA1A mutations: a retrospective single center study and review of the literature. Eur 7 Neurol 2019; 26: 66-e7.

24. Humbertclaude V, Krams B, Nogue E, et al. Benign paroxysmal torticollis, benign paroxysmal vertigo, and benign tonic upward gaze are not benign disorders. Dev Med Child Neurol 2018; 60: 1256-63.
5. Jen JC, Graves TD, Hess EJ, et al. Primary episodic ataxias: diagnosis, pathogenesis and treatment. Brain 2007; 130: 2484-93.

26. Headache Classification Committee of the International Headache Society (IHS). The International Classification of Headache Disorders, 3rd edition (beta version). Cephalalgia 2013; 33: 629-808.

27. Ouvrier R, Billson F. Paroxysmal tonic upgaze of childhood-a review. Brain Dev 2005; 27: 185-8.
28. Jung J, Testard H, Tournier-Lasserve E, et al. Phenotypic variability of episodic ataxia type 2 mutations: a family study. Eur Neurol 2010; 64: 1146.

29. Angelini C, Van Gils J, Bigourdan A, et al. Major intra-familial phenotypic heterogeneity and incomplete penetrance due to a CACNA1A pathogenic variant. Eur 7 Med Genet 2018; pii: S1769-7212(18)30335-5. ADM [https://doi.org/10.1016/j.ejmg.2018.08.011]. [Epub ahead of print] 